\title{
Comparison of emergent endoscopy and upper gastrointestinal series radiography in acute upper gastrointestinal haemorrhage
}

\author{
R. T. KELLER 1 AND G. M. LOGAN, JR \\ From the Cleveland Veterans Administration Hospital, Cleveland, Ohio 44106, U.S.A.
}

SUMMARY A prospective study of early diagnostic procedures in acute upper gastrointestinal haemorrhage was conducted in a series of 76 patients. The diagnostic procedures included upper gastrointestinal series radiography (UGIS) and endoscopy (ENDO). The clinicians' diagnosis and management improved in a statistically significant way as a result of the findings of endoscopy. The findings of UGIS did not significantly improve diagnostic accuracy and resulted in a statistically significant adverse effect on patient management. The results suggest that endoscopy is more effective in promoting early accurate diagnosis and management in patients with acute upper gastrointestinal haemorrhage.

Palmer (1952, 1969) and others (Katz et al., 1964; Hedberg, 1966; Cotton et al., 1973; Katon and Smith, 1973) have advocated the use of early endoscopic and radiological evaluation in the management of acute upper gastrointestinal haemorrhage. The advantage claimed for this approach is improved diagnostic accuracy due to the endoscopic visualization of the actively bleeding lesion. Using this vigorous diagnostic approach, Palmer reports a diagnostic accuracy of $60 \%$ with combined oesophagoscopy and gastroscopy; when radiographic studies were added, the rate of accuracy increased to 93\% (Palmer, 1969). With improved fibreoptic instruments, the endoscopic diagnostic accuracy has approached $92 \%$ (Katon and Smith, 1973).

The effect of early accurate diagnosis upon subsequent patient management has been studied by Scott (1959). He considered the effect of the vigorous diagnostic approach upon the clinician's initial diagnosis. He found that $30 \%$ of initial diagnoses, based on the history, the physical examination and past medical records were changed after the results of the diagnostic procedures were known. His findings suggest that at least $13 \%$ of the initial impressions would have led to inappropriate, and potentially harmful, management.

In the above clinical studies, the diagnostic criteria were not always independently and objectively re-

\footnotetext{
1Address for correspondence: Department of Internal Medicine, University of North Dakota, Grand Forks, North Dakota, 58202, U.S.A.

Received for publication 17 December 1975
}

viewed. Also, the endoscopic diagnosis was usually accepted as the final correct diagnosis. This approach can be misleading because of observer error (Conn et al., 1965). In an attempt to overcome the deficiencies in the existing studies, this prospective randomized trial was undertaken in a series of patients with acute upper gastrointestinal haemorrhage.

The present study was designed to (1) evaluate the relative diagnostic accuracy of emergent endoscopy and upper gastrointestinal series; (2) evaluate the effect of each diagnostic procedure, alone and in combination, on the subsequent management of the patient.

\section{Methods}

All patients admitted to the Cleveland Veterans Administration Hospital between 1 January 1972 and 31 December 1973 with acute upper gastrointestinal haemorrhage were included in the study. The criteria for acute haemorrhage was a history of haematemesis or melaena with bloody gastric aspirate within the preceding 24 hours. All patients in this study required a minimum of three units of blood or surgery within 24 hours after admission.

Seventy-six informed and consenting patients were admitted to the study. At the time of entry, the attending physician was asked to indicate his clinical diagnosis and proposed course of management. These decisions were based on the history, the physical examination, and the available medical records from previous hospital admissions. The 
attending physician's diagnosis and management choices were recorded on a standardized check-off style form (Figure). The patients were then randomly assigned to one of two groups. Group A (38 patients) received emergent endoscopy followed by upper gastrointestinal series radiography. Group B (38 patients) received upper gastrointestinal series radiography followed by endoscopy. In all cases, the diagnostic procedures were completed within 24 hours of entry to the study.

Endoscopic examination was performed by the gastrointestinal service residents and their faculties. The endoscopic procedure included examination of the oesophagus, stomach, and duodenum. When upper gastrointestinal series radiography preceded endoscopy, the stomach was lavaged before the gastroscopy to remove residual barium. Endoscopic films were obtained for review by an independent endoscopist.

The upper gastrointestinal series radiography was performed by the radiologist on call and was reviewed by a senior staff radiologist. The examination was performed in the usual fashion and in- cluded evaluation of the oesophagus, stomach, and duodenal bulb.

Both the endoscopist and the radiologist were informed that the patients had upper gastrointestinal haemorrhage but were given no other information about the patients' history, physical findings, laboratory data, or results of previous diagnostic studies.

After each diagnostic study, the attending physician received the diagnostic information on a standardized form. The attending physician recorded on another form his changes, if any, in both the clinical diagnosis and proposed plan of management.

After the patient's discharge or demise, the complete medical record was reviewed by an independent gastroenterologist. This review included the hospital course, the endoscopic films, radiography, and information obtained from surgical and/or pathological findings. The reviewer determined a final clinical diagnosis and a retrospective optimal plan of management for each patient. This final clinical diagnosis and treatment plan provided the standard

\section{PATIENT NAME DATE

$\begin{array}{lll}\text { PATIENT NUMBER } & \text { GROUP } & \text { SEQ. NUMBER }\end{array}$

AT THIS POINT IN THE TREATMENT OF YOUR PATIENT, WHAT DO YOU CONSIDER TO BE THE SOURCE OF BLEEDING ? PLEASE CHOOSE ONE OF THE FOLLOWING.

TYPE LESION

1. OESOPHAGITIS

2. OESOPHAGEAL ULCER

3. OESOPHAGEAL CANCER

4. OESOPHAGEAL VARICES

5. MALLORY-WEISS

6. HIATAL HERNIA/WITH REFLUX

7. HIATAL HERNIA/WITHOUT REFLUX

8. GASTRIC ULCER

9. GASTRIC EROSION

10. GASTRIC CARCINOMA

11. GASTRIC POLYP

12. DUODENAL ULCER

13. MARGINAL ULCER

14. HYPERTROPHIC GASTRITIS

15. ATROPHIC GASTRITIS

16. HAEMORRHAGIC GASTRITIS

17. OTHER (SPECIFY)

AT THIS POINT IN THE MANAGEMENT OF YOUR PATIENT, WHAT DO YOU CONSIDER TO BE THE BEST FORM OF MANAGEMENT? PLEASE CHOOSE ONE OF THE FOLLOWING.

MEDICAL MANAGEMENT

A. CONSERVATIVE MEDICAL MANAGEMENT, SURGERY NOT ANTICIPATED. MEDICAL MANAGEMENT TO INCLUDE:

\section{SENGSTAKEN TUBE}

2. GASTRIC COOLING BALLOON (

THORACIC INCISION () ABDOMINAL INCISION ()

SURGICAL MANAGEMENT

C. IMMINENT SURGERY AFTER STABILIZATION OF PATIENT.

THORACIC INCISION ( ) ABDOMINAL INCISION ( )

D. IMMEDIATE SURGERY (WITHIN 12 HOURS).

THORACIC INCISION () ABDOMINAL INCISION ( )

E. OTHER (SPECIFY).

THIS DECISION MADE BY: 1. HOUSE OFFICER （） 2. HOUSE OFFICER and VISITANT （）

3. SPECIALITY RESIDENT ( ) 4. SPECIALITY RESIDENT and VISITANT ( )

5. OTHER (PLEASE SPECIFY) ( )

Figure Diagnosis and management based on history and physical examination only. 
for evaluating the attending physicians' diagnosis and plan of management.

Of the 76 patients entered into the study, group A lost two patients and group B lost six patients because of lost records or incomplete forms. In addition, the protocol allowed the attending physician to omit one or both procedures. When a procedure was omitted, the patient was not included in the analysis of the accuracy of the omitted procedure.

The contigency table analyses were done by Chisquare test and the analyses of two-by-two tables utilized the Yates correction. The direction of changes in diagnosis and management decisions were studied by the McNemar test of significance of changes. However, if the expectation in one of the cells was less than five, the binomial test was substituted (Siegel, 1956). A level of rejection of 0.95 or greater was required to establish the significance of a result.

\section{Results}

In both groups, all patients were male and had a similar age distribution. The mean age for group A was 53.4 years and for group B 54.2 years. There was no significant difference between the two groups in the variables of technical adequacy of the diagnostic procedures, the type of haemorrhagic lesions, and severity of the individual bleeding.

The distribution of final diagnoses as determined by the independent reviewer is shown in Table 1 . The lesions are similar in each group. The distributions of lesions are not significantly different $(P>$ $0 \cdot 4)$.

The optimal management as determined by the reviewer is shown in Table 2; in the majority of the cases this was determined to be medical therapy. There are no significant differences in the two distri-

\begin{tabular}{lll}
\hline Diagnosis & Group A & Group B \\
\hline 1. Oesophagitis & 3 & 0 \\
2. Oesophageal ulcer & 1 & 1 \\
3. Oesophageal cancer & 0 & 0 \\
4. Oesophageal varices & 6 & 6 \\
5. Mallory-Weiss & 4 & 1 \\
6. Hiatal hernia, with reflux & 0 & 1 \\
7. Hiatal hernia, without reflux & 0 & 0 \\
8. Gastric ulcer & 4 & 4 \\
9. Gastric erosion & 7 & 12 \\
10. Gastric carcinoma & 0 & 0 \\
11. Gastric polyp & 0 & 0 \\
12. Duodenal ulcer & 7 & 3 \\
13. Marginal ulcer & 1 & 2 \\
14. Hypertrophic gastritis & 0 & 0 \\
15. Atrophic gastritis & 0 & 0 \\
16. Haemorrhagic gastritis & 2 & 1 \\
17. Other & 0 & 1 \\
18. None & 1 & 0 \\
\hline
\end{tabular}

Table 1 Final diagnosis

\begin{tabular}{lll}
\hline Management & Group A & Group B \\
\hline Medical & & \\
Sengstaken tube & 1 & 3 \\
Gastric cooling balloon & 0 & 0 \\
Continuous suction & 0 & 1 \\
$\quad$ Hourly antacids, normal medical & 26 & 22 \\
Elective surgery & & \\
Thoracic incision & 0 & 0 \\
$\quad$ Abdominal incision & 2 & 2 \\
Imminent surgery & 0 & 1 \\
Thoracic incision & 5 & 3 \\
Abdominal incision & 0 & 0 \\
Immediate surgery & 0 & 0 \\
$\quad$ Thoracic incision & 2 & 0 \\
Abdominal incision & 0 & \\
\hline
\end{tabular}

Table 2 Optimal management

butions of management decisions. The operative rate was $25 \%$ for group A and $19 \%$ for group B. This difference is not statistically significant. There was one death in each group for an overall mortality rate of $2.9 \%$.

\section{ACCURACY OF CLINICAL DIAGNOSIS}

The initial clinical impression was recorded before either diagnostic procedure was performed. This impression was based on the history, the physical examination, and available medical records. The accuracy of this diagnosis was determined by comparison with the retrospective final diagnosis established by the independent reviewer. In group A, the initial diagnostic impression was correct in $44.4 \%$ of the patients; in group B, the figure was $43.8 \%$.

The incidence of correct diagnosis by the attending physician after both procedures had been completed was $\mathbf{7 2 \cdot 2} \%$ for group A and $\mathbf{7 8 . 1} \%$ for group B. These differences are not statistically significant (P > 0.7).

\section{ACCURACY OF CLINICAL MANAGEMENT}

The accuracy of clinical management was determined by using the independent reviewer's retrospective judgement of optimum management as the standard. Before either procedure, the planned therapy was correct in $36.1 \%$ of the cases in group A and $37.5 \%$ of the cases in group B.

After both procedures had been completed, accuracy of clinical management in group A was $44.4 \%$ and in group B $59.4 \%$. These percentages do not differ significantly.

\section{DIFFERENCES IN DIAGNOSTIC PROCEDURES AND EFFECTS}

Using the reviewer-determined diagnosis as the standard, the overall accuracy rate of endoscopy was $72 \%$. The accuracy rate for upper gastrointestinal series radiography was $34 \%$. These rates are signifi- 
cantly different $(\mathrm{P}<0.0001)$. The accuracy of each procedure in diagnosing specific lesions is shown in Table 3. Endoscopy is significantly more accurate when performed before $(P<0.017)$ or after $(P<$ $0.0013)$ the upper gastrointestinal series radiography (Table 4).

When endoscopy was performed first (group A), an initial incorrect diagnosis was changed to a correct diagnosis in 15 cases and a correct initial diagnosis was changed to an incorrect diagnosis in two cases. This improvement is significant $(P<$ 0.003). Upper gastrointestinal series radiography performed after endoscopy changed a correct diagnosis to an incorrect diagnosis in three patients. This decrease in accuracy is not statistically significant (Table 5).

When the upper gastrointestinal series was performed first (group B), there was a change from a correct diagnosis to an incorrect diagnosis in three

\begin{tabular}{lcl}
\hline & ENDO & UGIS \\
\hline Oesophagitis & $2 / 3$ & $0 / 1^{*}$ \\
Oesophageal ulcer & $1 / 2$ & $0 / 1$ \\
Oesophageal varices & $11 / 12$ & $5 / 6$ \\
Mallory-Weiss & $4 / 5$ & $0 / 4$ \\
Hiatal hernia & $1 / 1$ & $1 / 1$ \\
Gastric ulcer & $4 / 7$ & $3 / 6$ \\
Gastric erosion & $13 / 18$ & $0 / 17$ \\
Duodenal ulcer & $6 / 8$ & $7 / 10$ \\
Marginal ulcer & $3 / 3$ & $1 / 2$ \\
Haemorrhagic gastritis & $0 / 3$ & $0 / 3$ \\
Other (Meckel's diverticulum) & $0 / 1$ & $0 / 1$ \\
None & $1 / 1$ & $1 / 1$ \\
\hline
\end{tabular}

Table 3 Accuracy of diagnostic procedures

*Patients not receiving a diagnostic procedure are excluded from the total for that procedure.

\begin{tabular}{lccccc}
\hline Diagnosis & \multicolumn{2}{c}{ First procedure } & & \multicolumn{2}{c}{ Second procedure } \\
\cline { 2 - 3 } \cline { 5 - 6 } & ENDO & UGIS & & ENDO & UGIS \\
\hline Correct & 23 & 10 & & 23 & 8 \\
Incorrect & 12 & 18 & & 6 & 17 \\
Not done & 1 & 4 & & 3 & 11 \\
P value & $<0.017$ & & $<0.0013$ \\
\hline
\end{tabular}

Table 4 Diagnostic accuracv of procedures

\begin{tabular}{|c|c|c|c|c|}
\hline \multirow[t]{2}{*}{ Type of change } & \multicolumn{2}{|c|}{$\begin{array}{l}\text { After } \\
\text { first procedure }\end{array}$} & \multicolumn{2}{|c|}{$\begin{array}{l}\text { After } \\
\text { second procedure }\end{array}$} \\
\hline & ENDO & UGIS & ENDO & UGIS \\
\hline $\begin{array}{l}\text { No change } \\
\text { Correct to incorrect } \\
\text { Incorrect to correct } \\
\text { Procedure omitted } \\
\text { P value (test of direction } \\
\text { of changes) }\end{array}$ & $\begin{array}{r}18 \\
2 \\
15 \\
1 \\
<0.003\end{array}$ & $\begin{array}{r}22 \\
3 \\
3 \\
4 \\
>0 \cdot 1\end{array}$ & $\begin{array}{r}14 \\
1 \\
10 \\
7 \\
<0.016\end{array}$ & $\begin{array}{r}20 \\
3 \\
1 \\
12 \\
>0.3\end{array}$ \\
\hline
\end{tabular}

Table 5 Analysis of change of clinician diagnosis from previous diagnosis patients and from an incorrect diagnosis to a correct diagnosis in three patients. Endoscopy, performed after upper gastrointestinal series radiography, changed an incorrect diagnosis to a correct diagnosis in 10 patients; a correct diagnosis was changed to an incorrect diagnosis in one patient. This is a statistically significant change toward improved accuracy (P < 0.016) (Table 5).

The management decisions were also influenced by the diagnostic procedures. In the patients who received endoscopy first (group A), there was significant improvement in the accuracy of proposed management as recorded by the attending physician immediately after endoscopy $(P<0.004)$. However, this was followed by a significant decline in the accuracy of management choices after upper gastrointestinal series radiography $(\mathrm{P}<0.016)$ (Table 6).

In the patients who received upper gastrointestinal series radiography first (group B), there was an increase in correct management decisions after each procedure. However, these increases were not statistically significant (Table 6).

\begin{tabular}{|c|c|c|c|c|}
\hline \multirow[t]{2}{*}{ Type of change } & \multicolumn{2}{|c|}{$\begin{array}{l}\text { After } \\
\text { first procedure }\end{array}$} & \multicolumn{2}{|c|}{$\begin{array}{l}\text { After } \\
\text { second procedure }\end{array}$} \\
\hline & ENDO & UGIS & ENDO & UGIS \\
\hline $\begin{array}{l}\text { None } \\
\text { Correct to incorrect } \\
\text { Incorrect to correct } \\
\text { Procedure not done } \\
\text { P value (test of direction } \\
\text { of changes) }\end{array}$ & $\begin{array}{r}21 \\
1 \\
13 \\
1 \\
<0.004=\end{array}$ & $\begin{array}{r}22 \\
2 \\
4 \\
4 \\
>0.6\end{array}$ & $\begin{array}{r}13 \\
4 \\
8 \\
7 \\
>0.3\end{array}$ & $\begin{array}{r}13 \\
10 \\
1 \\
12 \\
<0.016\end{array}$ \\
\hline
\end{tabular}

Table 6 Analysis of change in clinician management decisions

\section{Discussion}

An ideal study of the diagnostic approach to the patient with acute upper gastrointestinal haemorrhage would include a prospective analysis of the following groups: (1) patients diagnosed by history and physical examination alone; (2) patients diagnosed by endoscopy alone; (3) patients diagnosed by radiology alone; (4) patients diagnosed by a combination of diagnostic procedures.

Patients would be randomly assigned to each of these categories. The diagnostic accuracy would be determined by surgical findings exclusively. In the light of present knowledge, such a study is neither practical nor ethically feasible. Therefore, we chose a study design which would permit the patient to receive both diagnostic studies, altering only the sequence in which the studies were performed.

This study design allowed us to evaluate the attending clinician's accuracy of diagnosis and pro- 
posed clinical management at three distinct periods: (1) after the initial history and physical examination were performed; (2) after endoscopy was performed as a first and second diagnostic procedure; (3) after upper GI series radiography was performed as a first or second diagnostic procedure. The accuracy of the clinical diagnosis and choice of clinical management could then be compared with a diagnosis and treatment plan determined by an independent reviewer. The study design has the advantage of allowing the attending physician to omit (or the patient to decline) either of the diagnostic procedures. Obviously, the disadvantage in this approach is the possiblity of error by the final reviewer.

This study confirms that emergent endoscopy is more accurate than upper gastrointestinal series radiography. This was not an unexpected finding, having been noted by Hedberg (1966) and others.

Surprisingly, the study also revealed that the attending physician's diagnostic choice was influenced by the most recently performed diagnostic study regardless of its inherent accuracy. The diagnostic accuracy rates of the two groups attending physicians did not differ significantly after both procedures were completed. In group A, this reflects a tendency for inaccurate results of the upper gastrointestinal series radiography to adversely influence the more accurate diagnoses of the preceding endoscopy. In group $\mathrm{B}$, the endoscopic findings influenced attending physicians to correct the inaccurate diagnoses recorded after the upper gastrointestinal series. In both groups, the clinicians' diagnostic accuracy would have been improved if the upper gastrointestinal series radiography were omitted. These results suggest that the information provided from the upper gastrointestinal series radiography adversely affects the determination of correct diagnosis.

This finding arises largely from the error in the radiological diagnosis of mucosal lesions and erosions. In the group of 20 patients with mucosal lesions and erosions, the diagnoses made by radiology were: normal gastrointestinal tract (eight), gastric ulcer(six), duodenal ulcer (three), oesophageal varices (two), and hiatal hernia (one). There were no correct diagnoses of gastric erosions or mucosal lesions by upper gastrointestinal series radiography.

The tendency for upper gastrointestinal series radiography adversely to affect management was even more striking. Since the vigorous diagnostic approach consists of endoscopy followed by radiographic examination, the decline in accuracy of choice of management is of substantial clinical importance.

The present study supports the findings of Cotton et al. (1973), Hoare (1975), and others which suggest that endoscopy be utilized as a first diagnostic procedure in acute upper gastrointestinal haemorrhage. Radiological evaluation would follow endoscopy in those patients in whom no firm diagnosis had been established. In this series of emergent upper gastrointestinal haemorrhage, the best results were noted when endoscopy was performed as a first and only procedure.

The authors wish to acknowledge the assistance of Dr Benjamin Sullivan who reviewed gastroscopy films, Dr Errol Bellon who reviewed the results of upper gastrointestinal series radiography, and Dr Harold P. Roth who reviewed the complete medical record for each study patient.

\section{References}

Conn, H. O., Smith, H. W., and Brodoff, M. (1965). Observer variation in the endoscopic diagnosis of esophageal varices. New England Journal of Medicine, 272, 830-834.

Cotton, P. B., Rosenberg, M. T., Waldram, R. P. L., and Axon, A. T. R. (1973). Early endoscopy of oesophagus, stomach, and duodenal bulb in patients with haematemesis and melaena. British Medical Journal, 2, 505-509.

Hedberg, S. E. (1966). Early endoscopic diagnosis in upper gastrointestinal hemorrhage. Surgical Clinics of North America, 46, 499-512.

Hoare, A. M. (1975). Comparative study between endoscopy and radiology in acute upper gastrointestinal haemorrhage. British Medical Journal, 1, 27-30.

Katon, R. M., and Smith, F. W. (1973). Panendoscopy in the early diagnosis of acute upper gastrointestinal bleeding. Gastroenterology, 65, 728-734.

Katz, D., Douvres, P., Weisberg, H., McKinnon, W., and Glass, G. B. J. (1964). Early endoscopic diagnosis of acute upper gastrointestinal hemorrhage. Journal of the American Medical Association, 188, 405-408.

Palmer, E. D. (1952). Observations on the vigorous diagnostic approach to severe upper gastrointestinal hemorrhage. Annals of Internal Medicine, 36, 1484-1491.

Palmer, E. D. (1969). The vigorous diagnostic approach to upper-gastrointestinal tract hemorrhage. Journal of the American Medical Association, 207, 1477-1480.

Scott, N. M. (1959). Experiences with the 'vigorous diagnostic approach' to upper gastrointestinal hemorrhage. Annals of Internal Medicine, 51, 89-98.

Siegel, S. (1956). Nonparametric Statistics for the Behavioral Sciences. McGraw-Hill: New York. 